OPEN ACCESS

Edited by:

Raffaella Greco,

San Raffaele Hospital (IRCCS), Italy

Reviewed by:

Nicholas Short,

University of Texas MD Anderson

Cancer Center, United States

Panagiotis Tsirigotis,

National and Kapodistrian University of

Athens, Greece

${ }^{*}$ Correspondence:

Rong Guo

fccguor@zzu.edu.cn

Fei He

fcchef2@zzu.edu.cn

${ }^{\dagger}$ These authors have contributed equally to this work

Specialty section:

This article was submitted to Hematologic Malignancies,

a section of the journa

Frontiers in Oncology

Received: 16 May 2021

Accepted: 28 July 2021

Published: 16 August 2021

Citation:

Liu J, Jiang Z-X, Xie X-S, Wan D-M, Cao W-J, Wang M, Liu Z-Z, Dong Z-K, Wang $H-Q$, Lu R-Q, Zhang $Y-Y$,

Cheng Q-Q, Fan J-X, Li W, He F and Guo $R$ (2021) Maintenance Treatment With Low-Dose Decitabine After

Allogeneic Hematopoietic Cell

Transplantation in Patients With Adult Acute Lymphoblastic Leukemia.

Front. Oncol. 11:710545. doi: 10.3389/fonc.2021.710545

\section{Maintenance Treatment With Low- Dose Decitabine After Allogeneic Hematopoietic Cell Transplantation in Patients With Adult Acute Lymphoblastic Leukemia}

\author{
Jia Liu ${ }^{1,2+}$, Zhong-Xing Jiang ${ }^{1 \dagger}$, Xin-Sheng Xie ${ }^{1}$, Ding-Ming Wan ${ }^{1}$, Wei-Jie Cao ${ }^{1}$, \\ Meng Wang ${ }^{1}$, Zhen-Zhen Liu ${ }^{1}$, Zhen-Kun Dong ${ }^{1}$, Hai-Qiong Wang ${ }^{1}$, Run-Qing Lu ${ }^{1}$, \\ Yin-Yin Zhang ${ }^{1}$, Qian-Qian Cheng ${ }^{1}$, Ji-Xin Fan ${ }^{1}$, Wei $\mathrm{Li}^{1}{ }^{1}$, Fei He ${ }^{3 *}$ and Rong Guo ${ }^{1 *}$ \\ ${ }^{1}$ Department of Hematology, The First Affiliated Hospital of Zhengzhou University, Zhengzhou, China, ${ }^{2}$ Hematopoietic Stem \\ Cell Transplantation Center, Institute of Hematology and Blood Diseases Hospital, Chinese Academy of Medical Sciences \\ and Peking Union Medical College, Tianjin, China, ${ }^{3}$ Department of Cardiology, The First Affiliated Hospital of Zhengzhou \\ University, Zhengzhou, China
}

Background: Post-transplant relapse remains a principal leading cause of failure after allogeneic hematopoietic stem cell transplantation (allo-HSCT) in patients with adult acute lymphoblastic leukemia (ALL). The aim of this study was to investigate the efficacy and safety of low-dose decitabine on the prevention of adult ALL relapse after allo-HSCT.

Methods: In this prospective study, we enrolled 34 patients with ALL who underwent allo-HSCT from August 2016 to April 2020 and received low-dose decitabine maintenance treatment after transplantation. The primary objectives were cumulative incidence of relapse rate (CIR), overall survival (OS), and disease-free survival (DFS). The secondary objectives were graft-versus-host disease (GVHD) and safety.

Results: Among the enrolled 34 patients, 6 patients relapsed and 6 patients died. The 2year CIR, OS, and DFS were $20.2,77.5$, and $73.6 \%$, respectively. Subgroup analysis revealed the 2-year CIR, OS, and DFS rates of 12 patients with T-ALL/ymphoblastic lymphoma (LBL) were 8.3, 90, and 81.5\%, respectively. None of the seven patients with T-ALL relapsed. During maintenance treatment, only one patient (2.9\%) developed grade IV acute GVHD and four (11.8\%) patients had severe chronic GVHD. Thirty-two patients (94.1\%) developed only grade I to II myelosuppression, and two patients (5.8\%) developed grade III to IV granulocytopenia.

Conclusions: Maintenance treatment with low-dose decitabine after allo-HSCT may be used as a therapeutic option to reduce relapse in patients with adult ALL, especially in patients with T-ALL. Our findings require confirmation in larger-scale controlled trials.

Clinical Trial Registration: Chinese Clinical Trials Registry, identifier ChiCTR1800014888.

Keywords: allogeneic hematopoietic stem cell transplantation, decitabine, maintenance, prophylaxis, relapse, acute lymphoblastic leukemia 


\section{INTRODUCTION}

Post-transplant relapse remains a leading cause of failure after allogeneic hematopoietic stem cell transplantation (allo-HSCT). In patients with adult acute lymphoblastic leukemia (ALL), the risk of relapse-related death is higher, up to $30-54 \%$ (1-3). At present, donor lymphocyte infusion (DLI) is the most widely used management approach to relapse after transplantation. However, the downregulation of human leukocyte antigen II (HLA-II) molecules leads to the inability of donor T cells to recognize leukemic cells, which limits the use of DLI in the treatment of relapse after transplantation in patients with acute myeloid leukemia (AML) (4, 5 ), and the 3-year overall survival (OS) rate of these patients is only $10-20 \%$ (6). In particular, DLI is not ideal for treatment of ALL relapse after transplantation. Given the difficulty in the treatment of post-transplant relapse, preventing relapse is more important than treatment. Therefore, it is urgent to explore novel approaches to prevent leukemia relapse after allo-HSCT in adult ALL.

Different from the relapse occurring after traditional chemotherapy, the elimination of leukemic cells after allo-HSCT mainly depends on the graft-versus-leukemia (GVL) effect (7). A mechanism of post-transplantation relapse involves the downregulation of HLA-class II molecules induced by epigenetic silencing to reduce the GVL effect, and the downregulation of HLA-II expression is caused by hypermethylation of the promoter of the class II major histocompatibility complex (MHC) transactivator (CIITA) $(4,5,8)$. Most patients with T-ALL showed molecular loss of HLA-II (9), and only $5-17 \%$ of T-ALL expressed HLA-DR. A similar mechanism of loss of expression of HLA-II class molecules was also observed in B-cell lymphoma lines (10). In addition, many studies have shown that the degree of methylation of tumor suppressor genes is closely associated with the subtypes and prognosis of ALL (11-13). The above studies indicate the possibility of using hypomethylating agents (HMAs) as treatment in ALL after transplantation.

Both decitabine and azacitidine are HMAs and have been safely and effectively used for maintenance treatment of AML and myelodysplastic syndrome (MDS) after transplantation (14-20). The main effect of post-transplantation hypomethylation treatment is to prevent primary disease relapse and reduce graftversus-host disease (GVHD). The main mechanisms include increasing the number of regulatory $\mathrm{T}$ (Treg) cells and inducing cytotoxic CD8+ T cells $(21,22)$. Thus, considering the low hematological toxicity of maintenance treatment with low-dose decitabine after AML/MDS transplantation and the advantages of preventing relapse without affecting GVHD, we administered lowdose decitabine maintenance treatment to 34 patients with ALL after allo-HSCT. This was the first prospective study with the largest number of cases to date to describe the application of decitabine prophylaxis for relapse of transplanted ALL.

\section{MATERIALS AND METHODS}

\section{Study Design}

This was a single-center, prospective, single-arm study. Informed consent was obtained from all patients, and the study was conducted in accordance with the Declaration of Helsinki. The study protocol was approved by the Ethics Committee of the First Affiliated Hospital of Zhengzhou University. This study is registered at www.chictr.org.cn (ChiCTR1800014888).

\section{Patient Cohort}

Eligible candidates met all of the following inclusion criteria: (1) age $\geq 14$ years; (2) satisfied the diagnostic criteria of ALL or lymphoblastic lymphoma (LBL) in accordance with WHO 2016 guidelines (22); (3) patients underwent allo-HSCT in the First Affiliated Hospital of Zhengzhou University; (4) Eastern Cooperative Oncology Group (ECOG) performance status score $\leq 2$; (5) morphological complete remission (CR) before maintenance treatment; (6) estimated survival $\geq 3$ months.

The exclusion criteria included (1) concomitant diagnosis of another cancer; (2) concomitant uncontrolled fungal, bacterial, or viral infection; (3) hypersensitivity to decitabine; (4) diagnosis of human immunodeficiency virus infection or in active stage of hepatitis B or C virus infection; (5) brain dysfunction or severe mental illness; (6) concomitant disease(s) that may seriously endanger the safety of patients or affect the completion of this study; and (7) participation in another drug clinical trial(s) 1 month before the trial.

\section{Maintenance Treatment Regimen}

Maintenance treatment began more than 50 days after transplantation. This post-HSCT interval allows for adequate marrow recovery before starting decitabine. Decitabine $10 \mathrm{mg} / \mathrm{d}$ was planned for intravenous infusion $5 \mathrm{~h}$ on days 1 to 5 , and every 4 weeks for eight cycles, based on comprehensive analysis of previously relevant studies $(15,23,24)$. However, in the previous pretrial of low-dose decitabine maintenance treatment after AML/MDS transplantation at our center, patients who received decitabine for 5 days at $10 \mathrm{mg} / \mathrm{d}$ developed grade IV myelosuppression with granulocytic fever, requiring transfusion of approximately two units of platelets. Myelosuppression was alleviated, and blood products were not needed after adjusting to $10 \mathrm{mg} / \mathrm{d}$ for 3 days. Therefore, decitabine $10 \mathrm{mg} / \mathrm{d}$ (approximately $6 \mathrm{mg} / \mathrm{m}^{2} / \mathrm{d}$ ) was ultimately administered as an intravenous infusion for $5 \mathrm{~h}$ on days 1,3 , and 5 every 4 weeks for eight cycles in this study. It should be noted that the number of cycles increased by four to six cycles based on the patients' wishes, if they presented minimal residual disease (MRD) in the late period of maintenance treatment. The interval time of each cycle was also appropriately prolonged according to the recovery of the patient's hemogram.

Routine blood parameters, bone marrow (BM) smear, and MRD were examined before each cycle. MRD detection methods included flow cytometry (FCM), quantitative detection of certain genes or WT1 via polymerase chain reaction (PCR), and donor chimerism. In addition, patients with T-LBL also underwent regular positron emission tomography-computed tomography (PET/CT) examinations. Routine blood parameters were examined intermittently during the period of drug administration. Granulocyte colony stimulating factor (G-CSF) or blood products were administered as required according to 
the hemogram. Systemic anticancer drugs and other similar experimental treatments were banned during the trial. Withdrawal criteria included (1) patients who were unable to tolerate the treatment, (2) patients with relapse of primary disease, (3) patients developing severe GVHD or unacceptable infection, and (4) subjects who decided to withdraw from the trial.

\section{Evaluation Parameters}

Patients with ALL were divided into high-risk and standardrisk groups. High-risk ALL was defined based on at least one of the following criteria: (1) age $\geq 35$ years; (2) white blood cell (WBC) counts $>30 \times 10^{9} / \mathrm{L}$ for B-cell precursor (BCP)-ALL or $>100 \times 10^{9} /$ L for thymic T-ALL; (3) pro-B-ALL (CD10-), early T-ALL or mature T-ALL, hypodiploid ALL; (4) ALL with Philadelphia chromosome $(\mathrm{Ph})$, with the $\mathrm{t}(4,11)$ translocation, or with complex karyotype; and (5) failure to achieve CR after the first induction therapy (25). The risk classification of LBL was based on the international prognostic index (IPI) score. CR from ALL was defined as BM blasts $<5 \%$, no primitive naive lymphocytes in the peripheral blood, and no extramedullary lesions. CR of LBL was defined as PET/CT with no positive lesions and a normal BM smear. MRDpositive was defined as FCM $>0.01 \%$ of cells with a leukemia-associated aberrant immune phenotype in the $\mathrm{BM}$ sample or BCR-ABL transcript level $>0 \%$ in patients with $\mathrm{Ph}+$ ALL. Acute GVHD (aGVHD) and chronic GVHD (cGVHD) were graded according to accepted international criteria (26, 27). Considering that the platelet count was lower than the normal value and the WBC count was normal in some patients before treatment, hematological adverse reactions after treatment were evaluated based on changes in WBCs and were graded according to the National Cancer Institute Common Toxicity Criteria, version 3.0.

\section{Statistical Analysis}

The follow-up deadline was July 31, 2020. The primary endpoints were cumulative incidence of relapse rate (CIR), overall survival (OS), and disease-free survival (DFS) of patients who received low-dose decitabine maintenance treatment. The secondary endpoints were the incidence of GVHD after receiving decitabine and the safety of low-dose decitabine maintenance regimen. Statistical analyses were performed using SPSS software (version 21.0), R software package (version 4.0.0), and GraphPad Prism (version 8.0). Descriptive statistics were used to describe the general clinical features of patients. Data were censored at the time of relapse, non-relapse mortality (NRM), or last available follow-up. The cumulative incidence of relapse (CIR) and NRM were performed using the competing risk model, in which death without relapse was considered a competing risk of relapse. The disease-free survival (DFS) and OS were calculated using the Kaplan-Meier method. CIR was defined as time from transplantation to relapse. OS was defined as the time from transplantation to death from any cause. DFS was defined as time from transplantation to relapse or death, whichever occurred first. Statistical significance was defined as $P<0.05$.

\section{RESULTS}

\section{Patient Characteristics}

In total, 34 patients from our institution were enrolled between August 2016 and April 2020. The characteristics of patients are shown in Table 1. Our cohort comprised 34 patients with a median age of 20 years (range, 14-49 years), including 22 males and 12 females. Overall, 22 patients (64.7\%) had B-ALL, 7 (20.6\%) had T-ALL, and 5 (14.7\%) had T-LBL. Nine patients

TABLE 1 | Patients' characteristics ( $N=34)$.

\begin{tabular}{|c|c|}
\hline Characteristic & Value \\
\hline Age at HSCT, year, range (median) & $15-49(20)$ \\
\hline \multicolumn{2}{|l|}{ Sex, n (\%) } \\
\hline Male & $22(64.7)$ \\
\hline Female & $12(35.3)$ \\
\hline \multicolumn{2}{|l|}{ Diagnosis, n (\%) } \\
\hline B-ALL & $22(64.7)$ \\
\hline T-ALL/T-LBL & $7 / 5(35.3)$ \\
\hline \multicolumn{2}{|l|}{ Risk classification, n (\%) } \\
\hline High risk & $25(73.5)$ \\
\hline Standard risk & $9(26.5)$ \\
\hline \multicolumn{2}{|l|}{ Subtype, n (\%) some-positive (Ph+) ALL } \\
\hline $\mathrm{Ph}^{+} \mathrm{ALL}$ & 7 (20.6) \\
\hline $\mathrm{Ph}^{-} \mathrm{ALL}$ & $27(79.4)$ \\
\hline \multicolumn{2}{|l|}{ MRD after the $1^{\text {st }}$ induction, $\mathrm{n}(\%)$} \\
\hline Negative & $18(64.3)$ \\
\hline Positive & $10(35.7)$ \\
\hline \multicolumn{2}{|l|}{ MRD at allo-HSCT, n (\%) } \\
\hline Negative & $27(79.4)$ \\
\hline Positive & 7 (20.6) \\
\hline \multicolumn{2}{|l|}{ Disease status at allo-HSCT, n (\%) } \\
\hline CR1 & $31(91.2)$ \\
\hline $\mathrm{CR} 2$ & $3(8.8)$ \\
\hline \multicolumn{2}{|l|}{$\mathrm{HCl}-\mathrm{Cl}$ score, n (\%) } \\
\hline 0 & $21(61.8)$ \\
\hline 1 & $12(35.3)$ \\
\hline 2 & $1(2.9)$ \\
\hline \multicolumn{2}{|l|}{ EBMT risk score, n (\%) } \\
\hline 0 & $4(11.8)$ \\
\hline $1-2$ & $25(73.5)$ \\
\hline $3-4$ & $5(2.9)$ \\
\hline \multicolumn{2}{|l|}{ Conditioning regimen, n (\%) } \\
\hline $\mathrm{mBu} / \mathrm{Cy}$ & $26(76.5)$ \\
\hline TBI/Cy & $8(23.5)$ \\
\hline \multicolumn{2}{|l|}{ Transplant resource, n (\%) } \\
\hline PBSC & $31(91.2)$ \\
\hline PBSC+BM & $3(8.8)$ \\
\hline \multicolumn{2}{|l|}{ Donor/HLA match, n (\%) } \\
\hline Matched related & $21(61.8)$ \\
\hline Mismatched related & $11(32.4)$ \\
\hline Matched unrelated & $1(2.9)$ \\
\hline Mismatched unrelated & $1(2.9)$ \\
\hline CD $34^{+}$cells $\times 10^{6} / \mathrm{kg}$, range (median) & $1.52-16.3(5.7)$ \\
\hline MNC cells $\times 10^{8} / \mathrm{kg}$, range (median) & $1.2-11.5(5.3)$ \\
\hline Time of leukocyte engraftment, d (median) & 8-21 (13) \\
\hline Time of platelet engraftment, d (median) & $10-22(14)$ \\
\hline
\end{tabular}

ALL, acute lymphoblastic leukemia; LBL, lymphoblastic lymphoma; Ph, Philadelphia chromosome; MRD, minimal residual disease; HCT-Cl, hematopoietic cell transplantation comorbidity index; EBMT, European Society for Blood and Marrow Transplantation; Bu, busulfan; Cy, cyclophosphamide; TBI, total body irradiation; $\mathrm{mBu}$ / Cy, modified Bu/Cy; PBSC, peripheral blood stem cell; BM, bone marrow; MNC, mononuclear cell. 
(26.5\%) were at standard-risk, and 25 (73.5\%) were at high-risk (including five patients with T-LBL). Seven patients (20.6\%) were Philadelphia chromosome-positive $\left(\mathrm{Ph}^{+}\right)$, and 27 patients (79.4\%) were Philadelphia chromosome-negative $\left(\mathrm{Ph}^{-}\right)$. Excluding six patients due to missing MRD data from other hospitals at initial treatment, 10 (35.7\%) of 28 assessable patients were MRD positive (including two patients with non-CR after induction) and 18 patients (64.3\%) who became MRD-negative after the first induction chemotherapy. Seven patients $(20.6 \%)$ became MRD-positive, and 27 patients (79.4\%) achieved MRD negativity at transplantation. All patients received myeloablative conditioning, including 26 patients $(76.5 \%)$ receiving a modified busulfan $(\mathrm{Bu}) /$ cyclophosphamide $(\mathrm{Cy})$ regimen and $8(23.5 \%)$ patients receiving a total body irradiation (TBI)/Cy regimen (26). Prophylaxis against GVHD for all patients consisted of cyclosporine A and short-term methotrexate treatment with mycophenolate mofetil. In addition, patients without matched related donors were supplemented with anti-thymocyte globulin. The median number of infused CD34+ cells was $5.7 \times 10^{6} / \mathrm{kg}$ (range, $1.52-16.3 \times 10^{6} / \mathrm{kg}$ ), and the median number of infused MNC cells was $5.3 \times 10^{8} / \mathrm{kg}$ (range, $1.2-11.5 \times 10^{8} / \mathrm{kg}$ ). Neutrophils and platelets were implanted successfully in all patients. All patients achieved morphological CR and donor complete chimerism before maintenance treatment. Thirty patients (88.3\%) achieved MRD negativity, and four patients (11.7\%) were MRD positive before maintenance treatment (Table 2).

\section{Decitabine Exposure and MRD}

Outcomes of maintenance therapy with decitabine and the changes in MRD during this stage are shown in Table $\mathbf{2}$ and Figure 1. All four patients with MRD-positive disease before maintenance treatment turned negative after two or two cycles. Only three patients $(8.8 \%)$ had positive MRD once during maintenance therapy. The median time from transplantation to the start of maintenance treatment was 96 days (range, 51-175 days), and the median number of decitabine cycles for all patients was seven (range, 1-14). Overall, 14 patients $(41.1 \%)$ completed the study and entered the follow-up phase, including 12 patients with 8 cycles, 1 patient with 14 cycles, and 1 patient with 13 cycles of treatment. Patients No. 5 and No. 6 received more than eight cycles because they were MRD positive after the completion of eight cycles of maintenance treatment, and their MRD turned negative after an additional cycle of decitabine (Figure 1). At the data cut-off point, eight patients (23.5\%) were in the maintenance phase, including six patients who entered the study later and two patients due to the delay caused by the coronavirus disease 2019 (COVID-19) epidemic. The reasons for discontinuation included relapse $(\mathrm{n}=4,11.7 \%)$, GVHD $(\mathrm{n}=3$, $8.8 \%)$, and withdrawn consent $(\mathrm{n}=5,14.7 \%)$ (Table 2). Besides, as shown in Table 3, seven patients with $\mathrm{Ph}^{+}$ALL were treated with TKI maintenance during pre-transplantation chemotherapy, conditioning regimen, and post-transplantation maintenance therapy. Notably, TKI was suspended temporarily to reduce the risk of infection in patients with neutropenia after chemotherapy or transplantation.
TABLE 2 | Outcomes of transplantation and maintenance treatment $(\mathrm{N}=34)$.

\begin{tabular}{|c|c|}
\hline Outcomes & Data \\
\hline \multicolumn{2}{|l|}{ MRD before maintenance treatment, $\mathrm{n}(\%)$} \\
\hline Positive & $4(11.7)$ \\
\hline Negative & $30(88.3)$ \\
\hline Start time of decitabine, $\mathrm{d}$, median (range) & $96(51-175)$ \\
\hline No. of cycles, median (range) & $7(1-14)$ \\
\hline Completed study, n (\%) & $14(41.1)$ \\
\hline Maintenance period, n (\%) & $8(23.5)$ \\
\hline \multicolumn{2}{|l|}{ Reason for discontinuation, n (\%) } \\
\hline Withdrew consent & $5(14.7)$ \\
\hline Relapse & $4(11.7)$ \\
\hline GVHD & $3(8.8)$ \\
\hline \multicolumn{2}{|l|}{ Hematological toxicity, n (\%) } \\
\hline$|\sim| \mid$ & $32(94.1)$ \\
\hline$\| I|\sim| V$ & $2(5.8)$ \\
\hline Acute GVHD after maintenance treatment, n (\%) & $1(2.9)$ \\
\hline $\mid \sim \|$ & 0 \\
\hline III $\mid \mathrm{V}$ & $1(2.9)$ \\
\hline $\begin{array}{l}\text { Chronic GVHD after maintenance treatment, n (\%) nnnn(\%), n } \\
(\%) n(\%)\end{array}$ & $7(20.5)$ \\
\hline Mild & $3(8.8)$ \\
\hline Moderate & 0 \\
\hline Severe & $4(11.8)$ \\
\hline Relapse, n (\%) & $6(17.6)$ \\
\hline B-ALL & $5(14.7)$ \\
\hline T-LBL & $1(2.9)$ \\
\hline Cause of death, n (\%) & $6(17.6)$ \\
\hline Relapse & $4(11.7)$ \\
\hline Infection & $1(2.9)$ \\
\hline GVHD & $1(2.9)$ \\
\hline Duration of follow-up, d, range (median) & $\begin{array}{c}154-1,629 \\
(480.5)\end{array}$ \\
\hline
\end{tabular}

GVHD, graft-versus-host disease.

\section{Relapse}

At the data cut-off point (July 2020), the median follow-up time was 480.5 days (range, 154-1629 days) (Table 2). A total of six patients relapsed (17.6\%) with a median relapse time of 213 days (range, 156-551 days) after transplantation. Of these, five patients were at high risk (three patients with $\mathrm{Ph}^{+} \mathrm{B}$-ALL, two of which had T315I mutation at the time of relapse; one patient with pro-B-ALL; one patient with T-LBL in the leukemic phase had a WBC count $>100 \times 10^{9} / \mathrm{L}$ at diagnosis), and one patient with B-ALL was at standard risk (Table 4). Among the 14 patients who completed the study, only patient No. 2 presented extramedullary recurrence at 551 days after transplantation. Patient No. 16 with $\mathrm{Ph}^{+}$ALL only took imatinib but stopped decitabine on his own after five cycles. Relapse happened and T315I mutation was detected 2 months later, whereas this patient did not take ponatinib due to economic reasons. Patient No. 17 with $\mathrm{Ph}^{+}$ALL relapsed for a second time, and the T315I mutation was detected after two cycles. Patient No. 18 with $\mathrm{Ph}^{+}$ALL relapsed after five cycles and refused to test for mutations in the ABL kinase domain. Patients No. 3 with CR2 at HSCT relapsed after three cycles. After the six relapsed patients, one patient received chemotherapy; one patient received chemotherapy, TBI, and DLI in turn; two patients received chemotherapy; and two patients were discharged automatically. Finally, four patients died after relapse, and two patients were still alive (Table 4). Interestingly, none of the seven patients with T-ALL relapsed, 


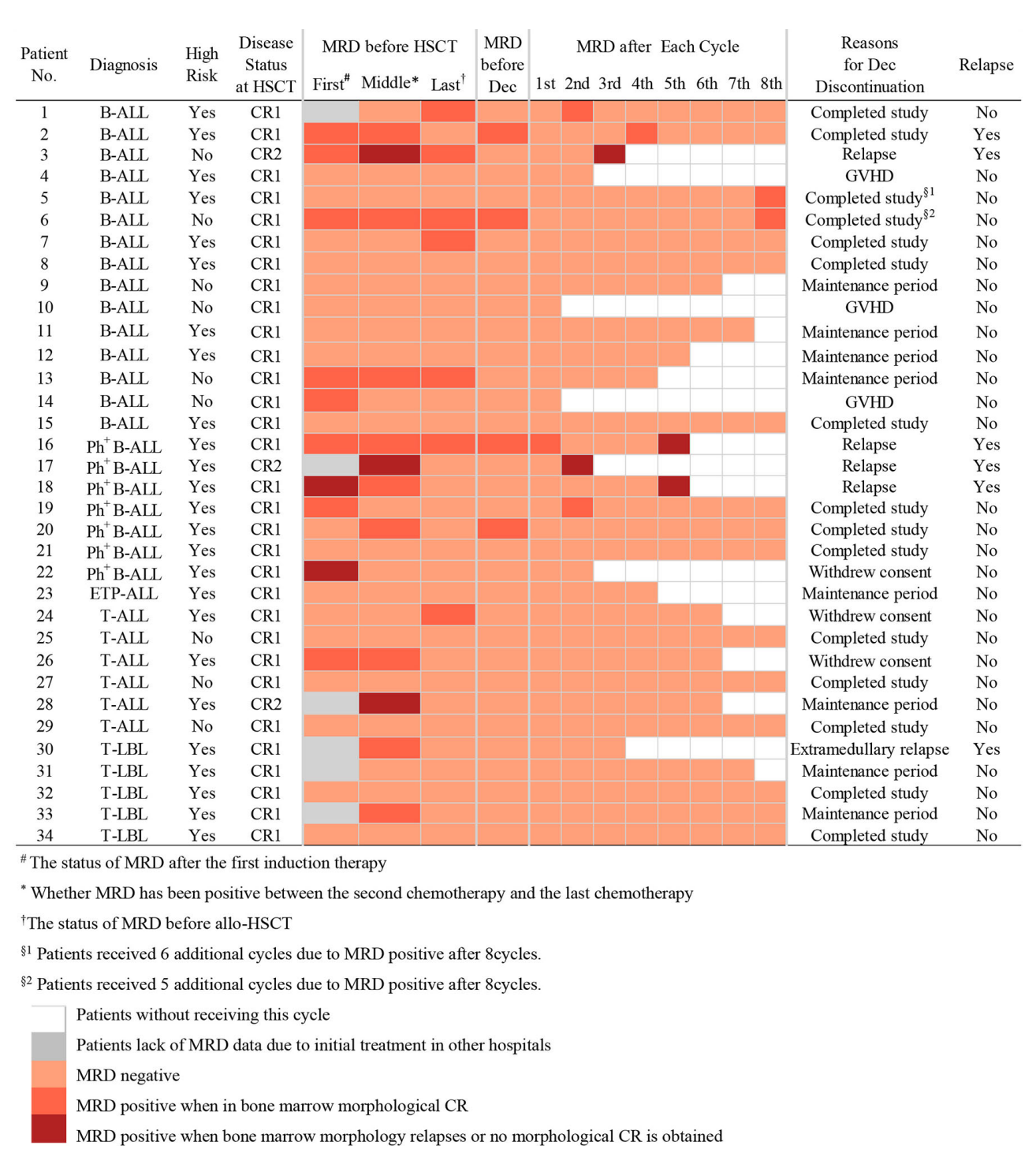

FIGURE 1 | Changes in MDR and decitabine exposure in patients.

including one patient with early T-cell precursor ALL (ETP-ALL) and three patients at high risk. In the end, the 2-year CIR of all 34 patients was $20.0 \%$, and the median CIR time was not reached (Figure 2A). Patients with T-ALL/LBL and B-ALL had a 2 -year CIR of 8.3 and $25.8 \%$, respectively $(\mathrm{P}=0.34)$. Patients at high risk and standard risk had a 2-year CIR of 22.4 and $12.5 \%$, respectively $(\mathrm{P}=$ 0.63). Patients with $\mathrm{Ph}^{+} \mathrm{ALL}$ and $\mathrm{Ph}^{-} \mathrm{ALL}$ had a 2 -year CIR of 42.8 and $14.5 \%$, respectively $(\mathrm{P}=0.08)$ (Figure $\mathbf{3 A}$ ).

\section{DFS and OS}

At the data cut-off point, $28(82.3 \%)$ of the 34 patients were alive $(82.3 \%)$, and 26 patients $(76.5 \%)$ were alive without relapse/ progression. Causes of death included relapse $(n=4)$, severe infection $(\mathrm{n}=1)$, and GVHD $(\mathrm{n}=1)$ (Table 2). The 2-year NRM was $6.3 \%$ (Figure 2A). The 2-year OS was $77.5 \%$, and the 2 -year DFS rate was $73.6 \%$ for the 34 patients (Figure 2B). The 2-year
OS of patients with T-ALL/LBL and B-ALL were 90 and $72.5 \%$, respectively $(\mathrm{P}=0.37)$. The 2 -year $\mathrm{OS}$ of patients at high risk and standard risk were 73.6 and $87.5 \%$, respectively $(\mathrm{P}=0.57)$. The 2 year $\mathrm{OS}$ of patients with $\mathrm{Ph}^{+} \mathrm{ALL}$ and $\mathrm{Ph}^{-}$ALL were 68.6 and $79.1 \%$, respectively $(\mathrm{P}=0.53$ ) (Figure 3B). For patients with $\mathrm{T}$ ALL/LBL and B-ALL, the 2-year DFS were 81.5 and $69.6 \%$, respectively $(\mathrm{P}=0.52)$. For patients at high risk and standard risk, the 2-year DFS were 68.8 and $87.5 \%$, respectively $(\mathrm{P}=0.36)$. For patients with $\mathrm{Ph}^{+}$ALL and $\mathrm{Ph}^{-}$ALL, the 2-year DFS were 57.1 and $77.3 \%$, respectively $(\mathrm{P}=0.23)$ (Figure $3 \mathrm{C}$ ).

\section{GVHD}

One patient $(2.9 \%)$ developed grade IV aGVHD, and seven (20.5\%) patients developed cGVHD (three with mild cGVHD and four severe cGVHD) during maintenance treatment phase (Table 2). Among the eight patients with GVHD after 
PatientNo.

TKI Before HSCT

TKI in Conditioning

TKI after HSCT

Relapse

Usage of TKI

Time of TKI Withdrawal (days)

\begin{tabular}{|c|c|c|c|c|c|c|}
\hline 16 & Dasatinib $(100 \mathrm{mg} / \mathrm{d})+$ chemotherapy & Dasatinib (100 mg/d) & 60 & Imatinib $(400 \mathrm{mg} / \mathrm{d})^{\star}$ & 276 & Yes \\
\hline 17 & Imatinib (400 mg/d) + chemotherapy & Imatinib (400 mg/d) & 61 & Imatinib (400 mg/d) & 170 & Yes \\
\hline 18 & Dasatinib $(100 \mathrm{mg} / \mathrm{d})+$ chemotherapy & Dasatinib (100 mg/d) & 59 & Dasatinib (100 mg/d) & 223 & Yes \\
\hline 19 & Imatinib (400 mg/d) + chemotherapy & Imatinib (400 mg/d) & 65 & Imatinib (400 mg/d) & 365 & No \\
\hline 20 & Imatinib (400 mg/d) + chemotherapy & Imatinib (400 mg/d) & 54 & Imatinib (400 mg/d) & 379 & No \\
\hline \multirow[t]{2}{*}{21} & Dasatinib (100 mg/d) + chemotherapy & Dasatinib (100 mg/d) & 66 & Dasatinib (100 mg/d) & 156 & No \\
\hline & & & 157 & Imatinib $(400 \mathrm{mg} / \mathrm{d})^{\#}$ & 365 & \\
\hline 22 & Imatinib $(300 \mathrm{mg} / \mathrm{d})^{\S}+$ chemotherapy & Imatinib (300 mg/d) & 57 & Dasatinib (100 mg/d) & 366 & No \\
\hline
\end{tabular}

TKI, tyrosine kinase inhibitor; ALL, acute lymphoblastic leukemia; HSCT, hematopoietic stem cell transplantation.

*As the patient suffered from diabetes mellitus complicated with fundus disease, dasatinib was replaced with imatinib after transplantation. "Dasatinib was replaced with imatinib at 157 days after transplantation because of repeated pleural effusion after taking dasatinib.

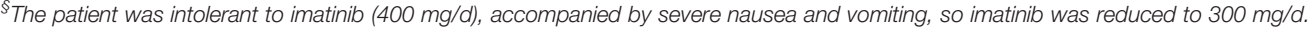

TABLE 4 | Characteristics and outcomes of six patients with relapse.

\begin{tabular}{|c|c|c|c|c|c|c|c|c|c|c|}
\hline $\begin{array}{l}\text { Patient } \\
\text { No. }\end{array}$ & Diagnosis & $\begin{array}{l}\text { High-Risk Factor at } \\
\text { Diagnosis }\end{array}$ & $\begin{array}{l}\text { Disease Status } \\
\text { at HSCT }\end{array}$ & $\begin{array}{l}\text { Starting Time of } \\
\text { Decitabine (days) }\end{array}$ & $\begin{array}{l}\text { Cycles of } \\
\text { Decitabine }\end{array}$ & $\begin{array}{l}\text { Reason for Discontinua- } \\
\text { tion of Decitabine }\end{array}$ & $\begin{array}{c}\text { Bone Marrow } \\
\text { Results at Relapse }\end{array}$ & $\begin{array}{l}\text { Time From HSCT to } \\
\text { Relapse (days) }\end{array}$ & $\begin{array}{c}\text { Treatment } \\
\text { After Relapse }\end{array}$ & $\begin{array}{c}\text { Overall } \\
\text { Survival } \\
\text { (days) }\end{array}$ \\
\hline 16 & B-ALL & $\begin{array}{l}\mathrm{Ph}^{+} \\
\text {WBC }>100 \times 10^{9} / \mathrm{L}\end{array}$ & CR1 & 63 & 5 & Withdrew consent & $\begin{array}{l}\text { Marrow blast } 97.6 \% \\
\text { T315/ mutation }\end{array}$ & 276 & $\begin{array}{l}\mathrm{DLI}+ \\
\text { chemotherapy }\end{array}$ & 433 \\
\hline 2 & B-ALL & $\mathrm{CD}_{10}^{-}$ & CR1 & 97 & 8 & Completed study & Extramedullary & 551 & $\begin{array}{l}\text { Chemotherapy; } \\
\text { TBI; } \\
\text { DLI }\end{array}$ & 725 \\
\hline 17 & B-ALL & $\begin{array}{l}\mathrm{Ph}^{+} \\
\text {Age }>35\end{array}$ & CR2 & 110 & 2 & Relapse & $\begin{array}{l}\text { Marrow blast } 42 \% \\
\text { T315/ mutation }\end{array}$ & 168 & $\begin{array}{l}\text { Automatic } \\
\text { discharge }\end{array}$ & 213 \\
\hline 3 & B-ALL & No & CR2 & 84 & 3 & Relapse & Marrow blast 49.6\% & 205 & $\begin{array}{l}\text { Automatic } \\
\text { discharge }\end{array}$ & 244 \\
\hline 30 & T-LBL & $\begin{array}{l}\text { Leukemic phase; } \\
\text { WBC }>100 \times 10^{9} / \mathrm{L}\end{array}$ & CR1 & 93 & 3 & Relapse & Extramedullary & 156 & Chemotherapy & $>205$ \\
\hline 18 & B-ALL & $\mathrm{Ph}^{+}$ & CR1 & 60 & 5 & Relapse & Marrow blast 16.4\% & 221 & Chemotherapy & $>427$ \\
\hline
\end{tabular}

WBC, white blood cell; $C R$, complete remission; DLI, donor lymphocyte infusion; HSCT, hematopoietic stem cell transplantation 


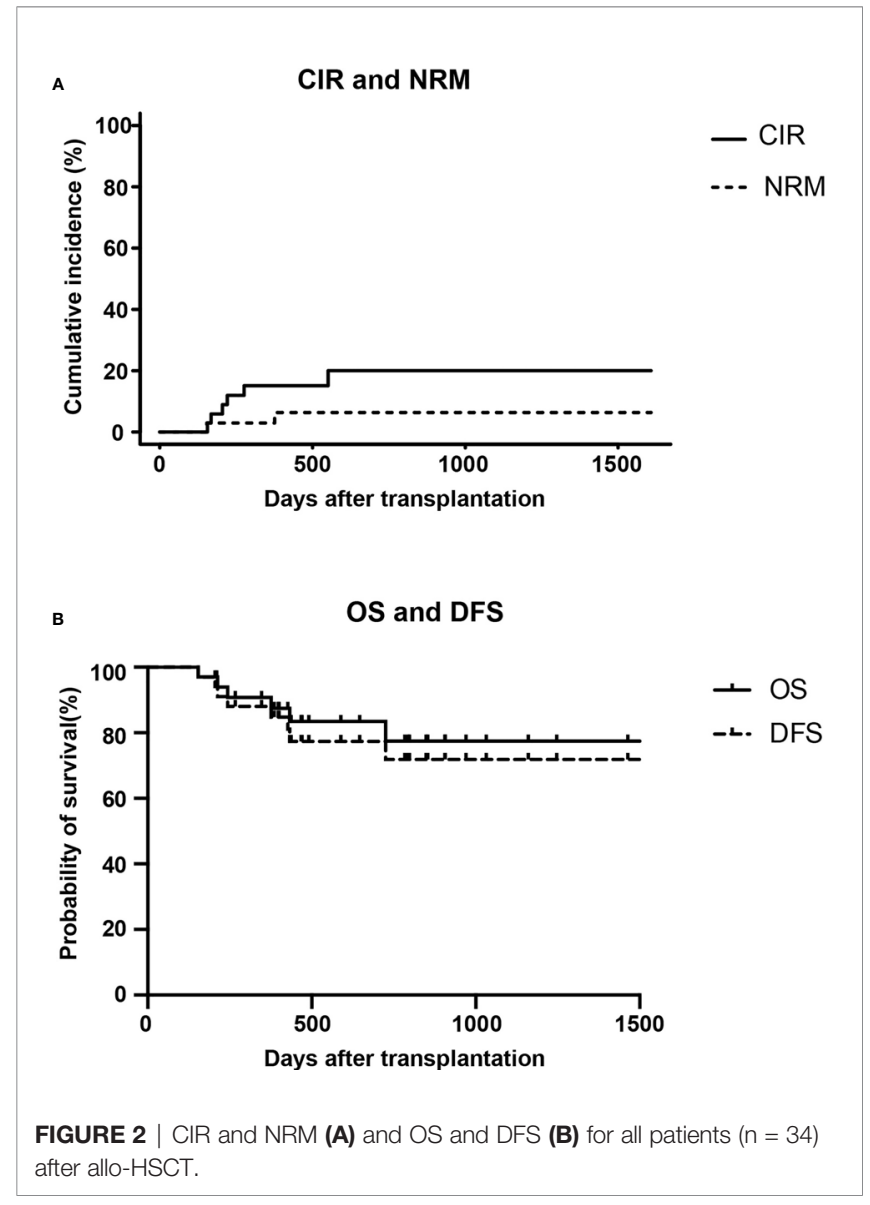

maintenance treatment, three patients had reduced the dose of immunosuppressive drugs before developing GVHD (one withdrew immunosuppressants and developed grade IV aGVHD during the second cycle; then, the patient stopped using decitabine and received intensive immunosuppressive treatment, but the response was poor and the patient eventually died). Two patients presented cGVHD before maintenance treatment. Of the remaining three patients, two developed cGVHD after one cycle and one developed cGVHD after three cycles of maintenance treatment. Among the eight patients with GVHD, organ involvement included the skin in eight patients, the intestinal tract in two patients, the liver in three patients, the oral cavity in three patients, and the eye in one patient. No significant worsening or relief was observed in patients with GVHD due to the use of decitabine.

\section{Adverse Events}

The main adverse event caused by low-dose decitabine was hematological toxicity. Among the 34 patients, 32 (94.1\%) developed grade I to II myelosuppression after maintenance treatment with low-dose decitabine (Table 4), and no infection occurred after timely administration of G-CSF. Only two patients (5.8\%) developed grade III to IV myelosuppression. Patient No. 9 developed degree IV granulocytopenia and mild pulmonary fungal infection after one cycle, which improved after administration of G-CSF and oral voriconazole. Patient No. 22

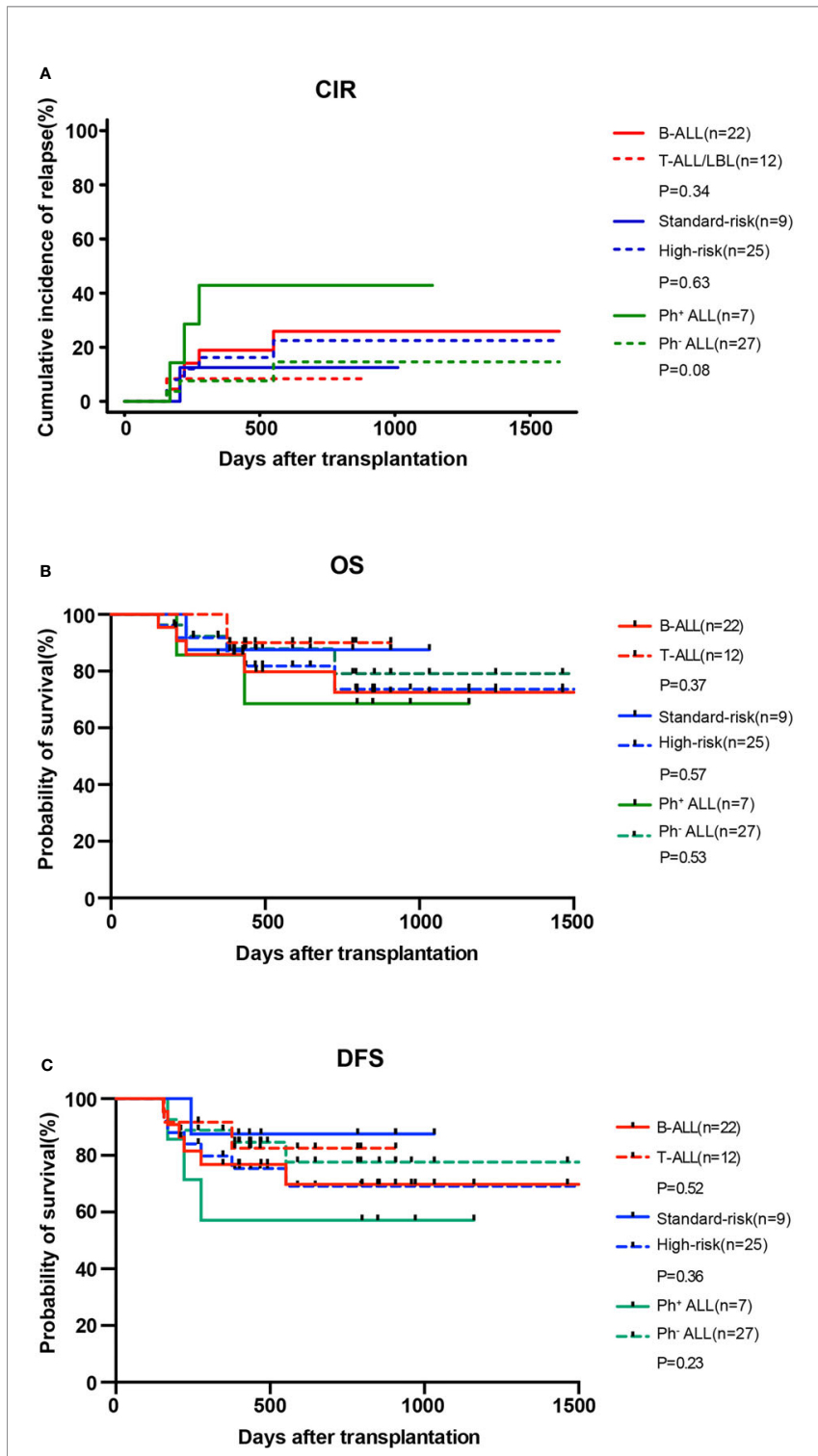

FIGURE 3 | CIR (A) and OS (B) and DFS (C) for patients with B-ALL $(n=22)$ and T-ALL/LBL $(n=12)$, patients at high risk $(n=25)$ and standard risk ( $n=9)$, and patients with $\mathrm{Ph}^{+} \operatorname{ALL}(\mathrm{n}=7)$ and $\mathrm{Ph}^{-} \operatorname{ALL}(\mathrm{n}=27)$ after allo-HSCT.

developed grade III granulocytopenia and mild pulmonary bacterial infection after one cycle, which improved after administration of G-CSF and oral azithromycin. Their granulocytes returned to normal after 14 days and 12 days of treatment, respectively. None of the patients required blood transfusion during the period of myelosuppression, and none of the patients interrupted treatment because of infection.

\section{DISCUSSION}

Disease relapse is a major therapeutic challenge in patients with adult ALL that have undergone allo-HSCT, and treatment 
options are limited. The risk of relapse-related death in this population was as high as about $30-54 \%(1-3,28)$, leaving preventing post-transplantation relapse necessary. At present, the downregulation of HLA-II molecules on leukemic cells caused by epigenetic silencing (such as the hypermethylation of CIITA) leads to immune escape of leukemic cells, which is a main mechanism of relapse post-transplantation $(4,8)$. Moreover, abnormalities in DNA methylation are common in ALL (11-13, 29, 30). Therefore, combined with the clear benefits of HAMs in maintenance therapy after AML/MDS transplantation $(14,15)$, we first evaluated the use of low-dose decitabine as maintenance therapy after allo-HSCT for adult ALL to reduce relapse and improve survival of this population. In this study, we achieved a 2-year CIR (20\%) that was lower than that reported in previous studies, and the 2-year OS (77.5\%) was satisfactory. Even in the high-risk group, the 2-year OS was $73.6 \%$. To some extent, our data also indicated that maintenance therapy with decitabine may be used as a treatment option to prevent relapse after ALL transplantation.

The prognosis of adult T-ALL is unsatisfactory, with a 5-year OS of only $30-50 \%(31-33)$. Furthermore, the prognosis of patients who relapse is poorer, with a reported 5-year OS of $5 \%$ (34). Although allo-HSCT has improved the prognosis of this population, there is still a CIR of $12.4 \%$ in the low-risk group and $41.2 \%$ in the high-risk group (35). However, the 2-year CIR of patients with T-ALL/LBL in our study was only $8.3 \%$, while OS and DFS were as high as 90 and $81.5 \%$, respectively. Surprisingly, none of the patients with T-ALL experienced relapse, which is encouraging. Katagiri et al. (36) also reported that successful maintenance treatment was achieved with azacitidine in a patient diagnosed with myeloid/lymphoid neoplasm with FGFR1 (located on chromosome 8p11.2) rearrangement after alloHSCT. In addition, ETP-ALL has a higher rate of remission failure and subsequent relapse than typical T-ALL (37). Meng et al. (38) reported that six patients with relapsed/refractory ETP-ALL were treated with decitabine combined with the CAG regimen (aclarubicin, cytarabine, and G-CSF), and five patients achieved CR. In this study, one patient with ETP-ALL initiated maintenance treatment with decitabine and has completed four cycles and is currently well at the date of last follow-up. The above evidence supports the feasibility of low-dose decitabine maintenance therapy in T-ALL.

Lockhart et al. (39) described a child with $\mathrm{Ph}^{+}$ALL having mixed donor chimerism and persistent BCR-ABL transcripts after allo-HSCT. There was no response to TKI treatment, but her clonal cytogenetic abnormalities were resolved after decitabine treatment. Cui et al. (40) also described 12 patients with relapse ALL after transplantation who were treated with decitabine alone or in combination with chemotherapy and DLI, and found that patients with $\mathrm{Ph}^{+}$ ALL achieved higher survival than patients with $\mathrm{Ph}^{-}$ALL. However, the effects of decitabine maintenance treatment on patients with $\mathrm{Ph}^{+}$ALL was not significant, and the 2-year CIR was much higher than that of patients with $\mathrm{Ph}^{-}$ALL in this study. Although all seven patients with $\mathrm{Ph}^{+} \mathrm{ALL}$ received oral
TKI after transplantation, three patients still relapsed. However, this may be related to the presence of the T315I mutation, as in two of the three relapsed patients the T315I mutation was detected at relapse, and one patient was not tested voluntarily. For patients with $\mathrm{Ph}^{+}$ALL after transplantation, exploring treatment with next-generation TKI may be more meaningful than low-dose decitabine.

HMAs can upregulate the expression of FOXP3 in CD4+CD25-T cells, thus increasing the number of Treg cells and mitigating GVHD $(41,42)$. In this study, only one patient developed grade IV aGVHD, while four patients presented severe cGVHD. Most cases occurred when immunosuppressants were reduced or prior to maintenance treatment. Only three patients stopped maintenance treatment because of GVHD. It is a pity that no aggravation or relief was observed in patients with GVHD due to the use of decitabine.

In this study, $94.1 \%$ patients developed grade I-II myelosuppression after receiving low-dose decitabine. Only two patients $(5.8 \%)$ developed grade III-IV granulocytopenia and mild pulmonary infection. None of the patients required blood transfusion, and no one stopped this trial because of hematological toxicity. Pusic et al. (15) divided 24 patients with AML/MDS into four groups after transplantation, and each group was given different doses of decitabine for maintenance therapy. The authors found that the $10 \mathrm{mg} / \mathrm{m}^{2} / \mathrm{d}$ group presented fewer hematological adverse reactions and that decitabine was well tolerated, which was similar to our results. Further, our study showed that maintenance treatment with lowdose decitabine after transplantation had low hematological toxicity and is well tolerated.

Obviously, this study also has some limitations. First, our patients exhibited selection bias. Risk of disease relapse after alloHSCT is a composite of multiple factors, including age, risk stratification at diagnosis, remission status at the time of transplantation, and duration of remission after transplantation. This study enrolled patients who were relatively young, and the sample population included $26.9 \%$ low-risk patients and several patients who were still in CR about 6 months after transplantation, which would lead to a better overall prognosis. Conversely, patients were enrolled without severe complications such as severe GVHD and were selected after day +50 of HSCT, which necessarily excluded those who relapsed early. Therefore, some transplanted patients were excluded because of early relapse or non-relapse mortality within the first 2 months. Secondly, this study did not detect changes in DNA methylation level before and after treatment, which would further support the use of HAMs. Finally, this study is limited by the small number of patients and lack of controls.

In conclusion, although the current data do not provide definitive evidence supporting the effects of low-dose decitabine maintenance treatment on the prevention of relapse after ALL transplantation, the overall results are encouraging and still indicate a positive trend. Low-dose decitabine maintenance treatment may be used as an option to prevent relapse after transplantation in patients with adult ALL, especially in patients 
with T-ALL. Our findings require confirmation in larger-scale controlled trials.

\section{DATA AVAILABILITY STATEMENT}

The original contributions presented in the study are included in the article/supplementary material. Further inquiries can be directed to the corresponding authors.

\section{ETHICS STATEMENT}

The studies involving human participants were reviewed and approved by the Ethics Committee of The First Affiliated Hospital of Zhengzhou University. Written informed consent to participate in this study was provided by the participants' legal guardian/next of kin.

\section{AUTHOR CONTRIBUTIONS}

RG, JL, and Z-XJ conceived, designed, and planned the study. All authors acquired the data. JL analyzed the data. JL and RG interpreted results. JL, FH, and RG drafted the report. RG, R-QL,

\section{REFERENCES}

1. Yonal-Hindilerden I, Kalayoglu-Besisik S, Gurses-Koc N, Hindilerden F, Sargin D. Allogeneic Hematopoietic Stem Cell Transplantation for Adult Acute Lymphoblastic Leukemia: Results From a Single Center, 1993-2011. Int J Hematol Oncol Stem Cell Res (2017) 11(1):58-62.

2. Lussana F, Intermesoli T, Gianni F, Boschini C, Masciulli A, Spinelli O, et al. Achieving Molecular Remission Before Allogeneic Stem Cell Transplantation in Adult Patients With Philadelphia Chromosome-Positive Acute Lymphoblastic Leukemia: Impact on Relapse and Long-Term Outcome. Biol Blood Marrow Transplant (2016) 22(11):1983-7. doi: 10.1016/ j.bbmt.2016.07.021

3. Wang L, Wang Y, Tang W, Dou H, Shan J, Hu J. The Superiority of Allogeneic Hematopoietic Stem Cell Transplantation From Unrelated Donor Over Chemotherapy for Adult Patients With High-Risk Acute Lymphoblastic Leukemia in First Remission. Int J Hematol (2013) 98 (5):569-77. doi: 10.1007/s12185-013-1442-5

4. Toffalori C, Zito L, Gambacorta V, Riba M, Oliveira G, Bucci G, et al. Immune Signature Drives Leukemia Escape and Relapse After Hematopoietic Cell Transplantation. Nat Med (2019) 25(4):603-11. doi: 10.1038/s41591-0190400-z

5. Christopher MJ, Petti AA, Rettig MP, Miller CA, Chendamarai E, Duncavage EJ, et al. Immune Escape of Relapsed Aml Cells After Allogeneic Transplantation. N Engl J Med (2018) 379(24):2330-41. doi: 10.1056/ nejmoa1808777

6. Schmid C, Labopin M, Nagler A, Bornhäuser M, Finke J, Fassas A, et al. Donor Lymphocyte Infusion in the Treatment of First Hematological Relapse After Allogeneic Stem-Cell Transplantation in Adults With Acute Myeloid Leukemia: A Retrospective Risk Factors Analysis and Comparison With Other Strategies by the EBMT Acute Leukemia Working Party. J Clin Oncol (2007) 25(31):4938-45. doi: 10.1200/JCO.2007.11.6053

7. Fleischhauer K, Shaw BE. HLA-DP in Unrelated Hematopoietic Cell Transplantation Revisited: Challenges and Opportunities. Blood (2017) 130 (9):1089-96. doi: 10.1182/blood-2017-03-742346

8. Wright KL, Ting JP. Epigenetic Regulation of MHC-II and CIITA Genes. Trends Immunol (2006) 27(9):405-12. doi: 10.1016/j.it.2006.07.007 and WL were involved in the critical revision of the manuscript. All authors contributed to the article and approved the submitted version.

\section{FUNDING}

This work was supported by the National Natural Science Foundation of China (81070445), Natural Science Foundation of Henan Province (No. 182300410301), Medical Science and Technology Research Project of Henan Province (2018020118), the Key Scientific Research Project of Higher Education of Henan Province (No. 18A320050), Science and Technology Plan of Henan Province (No. 182102310160), the Candidate Project of Henan Provincial Medical Science and Technology Research Funds Jointly Built by Province and Ministry (No. 2018010001).

\section{ACKNOWLEDGMENTS}

We thank Dr. Tao Li and Dr. Qiutang Zhang of the First Affiliated Hospital of Zhengzhou University for their help in laboratory testing, and we thank the patients who participated in this study and their families.

9. van Dongen JJ, Quertermous T, Bartram CR, Gold DP, Wolvers-Tettero IL, Comans-Bitter WM, et al. T Cell Receptor-CD3 Complex During Early T Cell Differentiation. Analysis of Immature T Cell Acute Lymphoblastic Leukemias (T-ALL) at DNA, RNA, and Cell Membrane Level. J Immunol (1987) 138:1260-9.

10. Holling TM, Schooten E, Langerak AW, van den Elsen PJ. Regulation of MHC Class II Expression in Human T-Cell Malignancies. Blood (2004) 103 (4):1438-44. doi: 10.1182/blood-2003-05-1491

11. Roman-Gomez J, Jimenez-Velasco A, Castillejo JA, Agirre X, Barrios M, Navarro G, et al. Promoter Hypermethylation of Cancer-Related Genes: A Strong Independent Prognostic Factor in Acute Lymphoblastic Leukemia. Blood (2004) 104(8):2492-8. doi: 10.1182/blood-2004-03-0954

12. Roman-Gomez J, Castillejo J, Jimenez A, Gonzalez M, Moreno F, Rodriguez, et al. 5' CpG Island Hypermethylation Is Associated With Transcriptional Silencing of the P21(CIP1/WAF1/SDI1) Gene and Confers Poor Prognosis in Acute Lymphoblastic Leukemia. Blood (2002) 99(7):2291-6. doi: 10.1182/ blood.v99.7.2291

13. Garcia-Manero G, Daniel J, Smith TL, Kornblau SM, Lee M, Kantarjian HM, et al. DNA Methylation of Multiple Promoter-Associated CpG Islands in Adult Acute Lymphocytic Leukemia. Clin Cancer Res (2002) 8(7):2217-24.

14. Gao L, Zhang Y, Wang S, Kong P, Su Y, Hu J, et al. Effect of rhG-CSF Combined With Decitabine Prophylaxis on Relapse of Patients With HighRisk Mrd-Negative AML After HSCT: An Open-Label, Multicenter, Randomized Controlled Trial. J Clin Oncol (2020) 38(36):4249-59. doi: 10.1200/JCO.19.03277

15. Pusic I, Choi J, Fiala MA, Gao F, Holt M, Cashen AF, et al. Maintenance Therapy With Decitabine After Allogeneic Stem Cell Transplantation for Acute Myelogenous Leukemia and Myelodysplastic Syndrome. Biol Blood Marrow Transplant (2015) 21(10):1761-9. doi: 10.1016/j.bbmt.2015.05.026

16. Ali N, Tomlinson B, Metheny L, Goldstein SC, Fu P, Cao S, et al. Conditioning Regimen Intensity and Low-Dose Azacitidine Maintenance After Allogeneic Hematopoietic Cell Transplantation for Acute Myeloid Leukemia. Leuk Lymphoma (2020) 61(12):2839-284. doi: 10.1080/10428194.2020.1789630

17. Marini C, Brissot E, Bazarbachi A, Isnard F, Lapusan S, Adaeva R, et al. Tolerability and Efficacy of Treatment With Azacytidine as Prophylactic or Preemptive Therapy for Myeloid Neoplasms After Allogeneic Stem Cell 
Transplantation. Clin Lymphoma Myeloma Leuk (2020) 20(6):377-82. doi: 10.1016/j.clml.2019.10.011

18. Oshrine BR, Shyr D, Hale G, Petrovic A. Low-Dose Azacitidine for Relapse Prevention After Allogeneic Hematopoietic Cell Transplantation in Children With Myeloid Malignancies. Pediatr Transplant (2019) 23(4):e13423. doi: 10.1111/petr.13423

19. de Lima M, Oran B, Champlin RE, Papadopoulos EB, Giralt SA, Scott BL, et al. CC-486 Maintenance After Stem Cell Transplantation in Patients With Acute Myeloid Leukemia or Myelodysplastic Syndromes. Biol Blood Marrow Transplant (2018) 24(10):2017-24. doi: 10.1016/j.bbmt.2018.06.016

20. Craddock C, Jilani N, Siddique S, Yap C, Khan J, Nagra S, et al. Tolerability and Clinical Activity of Post-Transplantation Azacitidine in Patients Allografted for Acute Myeloid Leukemia Treated on the RICAZA Trial. Biol Blood Marrow Transplant (2016) 22(2):385-90. doi: 10.1016/ j.bbmt.2015.09.004

21. Goodyear OC, Dennis M, Jilani NY, Loke J, Siddique S, Ryan G, et al. Azacitidine Augments Expansion of Regulatory T Cells After Allogeneic Stem Cell Transplantation in Patients With Acute Myeloid Leukemia (AML). Blood (2012) 119(14):3361-9. doi: 10.1182/blood-2011-09-377044

22. Goodyear O, Agathanggelou A, Novitzky-Basso I, Siddique S, McSkeane T, Ryan G, et al. Induction of a CD8+ T-Cell Response to the MAGE Cancer Testis Antigen by Combined Treatment With Azacitidine and Sodium Valproate in Patients With Acute Myeloid Leukemia and Myelodysplasia. Blood (2010) 116(11):1908-18. doi: 10.1182/blood-2009-11-249474

23. Karahoca M, Momparler RL. Pharmacokinetic and Pharmacodynamic Analysis of 5-Aza-2'-Deoxycytidine (Decitabine) in the Design of its DoseSchedule for Cancer Therapy. Clin Epigenet (2013) 5(1):3. doi: 10.1186/18687083-5-3

24. Han S, Kim Y, Lee J, Jeon S, Hong T, Park G, et al. Model-Based Adaptive Phase I Trial Design of Post-Transplant Decitabine Maintenance in Myelodysplastic Syndrome. J Hematol Oncol (2015) 8(1):118. doi: 10.1186/ s13045-015-0208-3

25. Gökbuget N, Hoelzer D. Treatment of Adult Acute Lymphoblastic Leukemia. Semin Hematol (2009) 46(1):64-75. doi: 10.1053/j.seminhematol.2008.09.003

26. Przepiorka D, Weisdorf D, Martin P, Klingemann HG, Beatty P, Hows J, et al. 1994 Consensus Conference on Acute GVHD Grading. Bone Marrow Transplant (1995) 15: (6):825-8.

27. Filipovich AH, Weisdorf D, Pavletic S, Socie G, Wingard JR, Lee SJ, et al. National Institutes of Health Consensus Development Project on Criteria for Clinical Trials in Chronic Graft-Versus-Host Disease: I. Diagnosis and Staging Working Group Report. Biol Blood Marrow Transplant (2005) 11(12):945-56. doi: 10.1016/j.bbmt.2005.09.004

28. Ribera J, Morgades M, Ciudad J, Montesinos P, Esteve J, Genescà E, et al. Chemotherapy or Allogeneic Transplantation in High-Risk Philadelphia Chromosome-Negative Adult Lymphoblastic Leukemia. Blood (2021) 137 (14):1879-94. doi: 10.1182/blood.2020007311

29. Borssén M, Palmqvist L, Karrman K, Abrahamsson J, Behrendtz M, Heldrup J, et al. Promoter DNA Methylation Pattern Identifies Prognostic Subgroups in Childhood T-Cell Acute Lymphoblastic Leukemia. PloS One (2013) 8(6): e65373. doi: 10.1371/journal.pone.0065373

30. Kimura S, Seki M, Kawai T, Goto H, Yoshida K, Isobe T, et al. DNA Methylation-Based Classification Reveals Difference Between Pediatric TCell Acute Lymphoblastic Leukemia and Normal Thymocytes. Leukemia (2020) 34(4):1163-8. doi: 10.1038/s41375-019-0626-2

31. Tavernier E, Le Q, de Botton S, Dhédin N, Bulabois C, Reman O, et al. Secondary or Concomitant Neoplasms Among Adults Diagnosed With Acute Lymphoblastic Leukemia and Treated According to the LALA-87 and LALA94 Trials. Cancer (2007) 110(12):2747-55. doi: 10.1002/cncr.23097

32. Rowe JM. Induction Therapy for Adults With Acute Lymphoblastic Leukemia: Results of More Than 1500 Patients From the International ALL Trial: MRC UKALL XII/ECOG E2993. Blood (2005) 106(12):3760-7. doi: 10.1182/blood-2005-04-1623
33. Kantarjian H, Thomas D, O’Brien S, Cortes J, Giles F, Jeha S, et al. Long-Term Follow-Up Results of Hyperfractionated Cyclophosphamide, Vincristine, Doxorubicin, and Dexamethasone (Hyper-CVAD), a Dose-Intensive Regimen, in Adult Acute Lymphocytic Leukemia. Cancer (2004) 101 (12):2788-801. doi: $10.1002 / \mathrm{cncr} .20668$

34. Fielding AK, Richards SM, Chopra R, Lazarus HM, Litzow MR, Buck G, et al. Outcome of 609 Adults After Relapse of Acute Lymphoblastic Leukemia (ALL); an MRC UKALL12/ECOG 2993 Study. Blood (2007) 109(3):944-50. doi: 10.1182/blood-2006-05-018192

35. Xu M, Liu H, Liu Y, Ma X, Qiu H, Fu C, et al. Gene Mutations and Pretransplant Minimal Residual Disease Predict Risk of Relapse in Adult Patients After Allogeneic Hematopoietic Stem-Cell Transplantation for T Cell Acute Lymphoblastic Leukemia. Leuk Lymphoma (2019) 60(11):2744-53. doi: 10.1080/10428194.2019.1597270

36. Katagiri S, Umezu T, Azuma K, Kobayashi C, Akahane D, Suguro T, et al. Maintenance 5-Azacytidine Therapy by MRD Monitoring After Allogeneic HSCT in Myeloid/Lymphoid Neoplasms With FGFR1 Rearrangement. Bone Marrow Transplant (2019) 54(7):1148-50. doi: 10.1038/s41409-0190436-1

37. Jain N, Lamb AV, O’Brien S, Ravandi F, Konopleva M, Jabbour E, et al. Early T-Cell Precursor Acute Lymphoblastic Leukemia/Lymphoma (ETP-ALL/ LBL) in Adolescents and Adults: A High-Risk Subtype. Blood (2016) 127 (15):1863-9. doi: 10.1182/blood-2015-08

38. Meng T, Yao Y, Xu Y, Xue S, Han Y, Tang X, et al. Salvage Therapy With Decitabine in Combination With Granulocyte Colony-Stimulating Factor, Low-Dose Cytarabine, and Aclarubicin in Patients With Refractory or Relapsed Early T-Cell Precursor Acute Lymphoblastic Leukemia. Hematol Oncol (2020) 38(5):834-7. doi: 10.1002/hon.2783

39. Lockhart S, McDonald L, Rytting M, Chan KW. Clonal Cytogenetic Abnormalities After Tyrosine Kinase Inhibitor Therapy in Ph+ All Resolution After Decitabine Therapy. Pediatr Blood Cancer (2012) 59 (3):573-5. doi: 10.1002/pbc.23318

40. Cui J, Xiao Y, You Y, Shi W, Li Q, Luo Y, et al. Decitabine for Relapsed Acute Lymphoblastic Leukemia After Allogeneic Hematopoietic Stem Cell Transplantation. Curr Med Sci (2017) 37(5):693-8. doi: 10.1007/s11596017-1790-0

41. Choi J, Ritchey J, Prior JL, Holt M, Shannon WD, Deych E, et al. In Vivo Administration of Hypomethylating Agents Mitigate Graft-Versus-Host Disease Without Sacrificing Graft-Versus-Leukemia. Blood (2010) 116 (1):129-39. doi: 10.1182/blood-2009-12-257253

42. Cooper ML, Choi J, Karpova D, Vij K, Ritchey J, Schroeder MA, et al. Azacitidine Mitigates Graft-Versus-Host Disease via Differential Effects on the Proliferation of Teffectors and Natural Regulatory T Cells In Vivo. J Immunol (2017) 198(9):3746-54. doi: 10.4049/jimmunol.1502399

Conflict of Interest: The authors declare that the research was conducted in the absence of any commercial or financial relationships that could be construed as a potential conflict of interest.

Publisher's Note: All claims expressed in this article are solely those of the authors and do not necessarily represent those of their affiliated organizations, or those of the publisher, the editors and the reviewers. Any product that may be evaluated in this article, or claim that may be made by its manufacturer, is not guaranteed or endorsed by the publisher.

Copyright $\odot 2021$ Liu, Jiang, Xie, Wan, Cao, Wang, Liu, Dong, Wang, Lu, Zhang, Cheng, Fan, Li, He and Guo. This is an open-access article distributed under the terms of the Creative Commons Attribution License (CC BY). The use, distribution or reproduction in other forums is permitted, provided the original author(s) and the copyright owner(s) are credited and that the original publication in this journal is cited, in accordance with accepted academic practice. No use, distribution or reproduction is permitted which does not comply with these terms. 